\title{
Introduction: the Role of Agricultural Technologies in Tropical Deforestation
}

\section{What Kind of World do we Live in?}

Imagine a world where the demand for food and other agricultural products is constant or increases regularly as populations and incomes grow. Land can only be used for agriculture or forest. Then the only ways to keep more land in forest are to increase agricultural yields, reduce population growth or depress incomes. The amount of land devoted to agriculture equals the total demand for agricultural products divided by the average yield (output per hectare). Technological progress resulting in higher yields means less land in agriculture and more in forest.

Now imagine another world. Farmers who live in this second world will do anything they can to increase their profits. They can sell all the produce they want for a fixed price and obtain all the land, labour and credit they need, also for a fixed price. What will these farmers do if a profitable technological change increases their yields or lowers their input costs? They will certainly cultivate more land since farming has become more profitable. If agriculture and forest are still the only possible land uses, forest cover will decline. Unlike in our first world, technological progress leads to forest destruction.

Which world do we live in? Does technological progress in agriculture protect or endanger tropical forests? Do we face a 'win-win' situation between farmer incomes and food production on the one hand and forest conservation on the other? Or is there a trade-off between the two?

This book attempts to answer these questions. The answers depend heavily on the assumptions we make about type of technology, farmer characteristics, market conditions, policy environment and agroecological 
conditions, among other things. Thus, the real question is when does technological progress lead to greater or lower tropical deforestation? We want to identify technologies and contexts that are likely to produce win-win outcomes and help decision-makers that face serious trade-offs to make hard choices.

The book contains cases from Latin America, sub-Saharan Africa and South-East Asia, in addition to two studies on the historical experience of developed countries in Europe and the USA. They cover a wide range of technological changes (new crops, higher-yielding varieties, mechanization, irrigation, fertilizers, pest control, etc.) in different agricultural systems (shifting cultivation, permanent upland cultivation, irrigated farming or lowland cultivation and cattle ranching). The comparative approach permits us to distil the key conditioning factors in the technologydeforestation link.

\section{Policies Based on False Assumptions?}

Higher agricultural production and forest conservation are both vital for achieving sustainable development in poor countries. Most people understand and appreciate the importance of higher agricultural production to improve farmers' well-being. For some time researchers have debated about what role agriculture plays in economic development, but it is now widely recognized that good agricultural performance is key for high economic growth (World Bank, 1991). Growing evidence also supports the idea that agriculturally driven growth reduces poverty and improves income distribution more than industrially driven growth (Mellor, 1999).

At the same time, international concern about the adverse consequences of tropical deforestation is also rising. Forest clearing contributes to climate change, biodiversity loss, reduced timber supply, flooding, siltation and soil degradation. This in turn affects economic activity and people's livelihoods. The Food and Agriculture Organization (FAO, 1997) estimates that 12.7 million ha of tropical forest was lost each year during the first half of the 1990s. In some cases deforestation is probably appropriate, in the sense that the benefits are higher than the social costs. However, in many it is not.

Current policies and institutional arrangements often lead to inappropriate deforestation, in part due to false assumptions about the causal relations that link the policies to forest clearing (for an elaboration, see Angelsen and Kaimowitz, 1999). One such dubious assumption is that higher productivity and better agricultural technologies will almost always benefit forest conservation. This 'win-win' assumption has dominated recent policy debates on agricultural technologies and deforestation. It is grounded in various hypotheses, which we critically review below. 


\subsection{The Borlaug hypothesis}

By definition, average yield multiplied by area gives total production. Thus, if we keep global food demand fixed, then higher average yield reduces agricultural area, as in our first world discussed above. With food demand expected to grow steadily over the next decades, one could argue that using new technologies to make agriculture more intensive is the only way to avoid rising pressure on tropical forests. This sort of thinking recently led the former vice-president of the World Bank to state that Central African agriculture needs 4\% productivity growth annually to save the region's rain forest (Serageldin, quoted in Gockowski et al., 2000).

This line of reasoning also underlies the position that the Green Revolution has had a positive effect on forest cover. Green-Revolution enthusiasts often stress that new varieties of rice, wheat and maize, combined with greater use of fertilizers, irrigation and pesticides, helped save millions of hectares of tropical forest. They argue that, without a Green Revolution, Asian countries in particular would have had to expand their cropland to feed their population. We refer to this argument as the Borlaug hypothesis, in recognition of the key role that Norman Borlaug, the 'father of the Green Revolution', had in promoting it.

The Borlaug hypothesis probably holds for aggregate food production at the global level, at least as long as one assumes that no land uses exist except forest and agricultural land. However, it is much less clear that it applies to technological changes that affect specific products, particularly at the local and regional levels. Technological change at the forest frontier often has minimal impact on agricultural prices. Therefore, the increased profitability effect may dominate and lead to greater agricultural expansion.

Perhaps more importantly, forest, cropland and pasture are not the only land uses that exist. There are large areas of fallow, savannah, brush and other land uses out there. This means that increases or decreases in cropland and pasture may or may not lead to a corresponding change in forest cover. It may simply be that more fallow gets put back into agricultural use or vice versa.

\subsection{The subsistence hypothesis}

The micro-level version of the Borlaug hypothesis is what we refer to as the subsistence hypothesis. If one assumes that smallholder farmers: (i) live close to the subsistence level of consumption; (ii) are primarily concerned with meeting that subsistence target; (iii) only use family labour on their farms; and (iv) have no alternative uses for that family labour, then technological progress should reduce deforestation. Higher yields allow farmers to get their subsistence income from a smaller area. In addition, if the new technology is labour-intensive, the farmer will have to reduce the amount of land he or she cultivates to adopt it. 
The subsistence hypothesis underlies many integrated conservation and development projects (ICDP). Higher income from agriculture (or other activities) is supposed to reduce farmers' need to encroach upon protected areas. Similarly, the assumption that agroforestry - as a way of intensifying land use - will limit conversion of primary forests to slash-and-burn agriculture has been a key element of the Alternatives to Slash-and-Burn (ASB) programme coordinated by the International Centre for Research on Agroforestry (ICRAF) (ASB, 1994).

One can dispute the subsistence hypothesis on several accounts. Most farmers probably do not exhibit the 'limited wants' or 'full belly' preferences that the hypothesis assumes. They aspire to give their children a proper education, buy a new bicycle or maybe a motorcycle, put a proper roof over their head, etc. Thus, if a new technology presents fresh economic opportunities, farmers are likely to expand their agricultural land unless their labour and/or capital constraints keep them from doing so. Although they are far from perfect, local labour markets exist. Farmers can usually sell some labour off-farm and can hire labour. In addition, technologies that create new economic opportunities can stimulate migration to forest frontiers, increasing forest conversion. As the ASB-Indonesia programme has acknowledged in a recent assessment of the issue:

It is naïve to expect that productivity increases necessarily slow forest conversion or improve the environment. Indeed quite the opposite is possible, since increased productivity of forest-derived land uses also increases the opportunity costs of conserving natural forests. These increased returns to investment can spur an inflow of migrants or attract large-scale land developers and thereby accelerate deforestation ... ASB research in Indonesia has shown that land use change normally involves tradeoffs between global environmental concerns and the objectives of poverty alleviation and national development.

(Tomich et al., 2000)

\subsection{The economic development hypothesis}

The Borlaug hypothesis applies at the international or global (macro) level. The subsistence hypothesis focuses on the household or village (micro) level. We can also identify a third argument that links technological progress in agriculture and forest conservation at the regional or national (meso) level. The argument goes as follows. Higher productivity in agriculture - of which improved technologies are a crucial element - contributes to economic development and growth, which, in turn, is associated with other changes that limit forest conversion. These include reduced poverty and population growth, more and higher-paying off-farm jobs, increased demand for environmental services and products from managed forests and higher government capacity to enforce environmental regulations. 
This chain of causation provides the underlying rationale for the so-called environmental Kuznets curve (EKC), which posits the existence of a bellshaped relation between income and environmental degradation. At early stages of economic development, when per capita incomes are low, growth exacerbates environmental problems, but eventually growth helps reduce these problems. This idea is also linked to the forest transition hypothesis, which suggests that the decline in forest cover will eventually level out as countries develop and forest cover will slowly increase.

Again, we have a plausible positive link between technological progress in agriculture and forest conservation. But does it pass the empirical test? The historical experience of the developed countries provides some support for the forest transition hypothesis. Nevertheless, most tropical forest-rich countries are decades away from the inflection point. Economic growth in these countries provides better infrastructure, which stimulates deforestation. Reduced poverty might relax farmers' labour and capital constraints, which previously had effectively limited deforestation. Higher demand for agricultural products stimulates agricultural encroachment. The political priorities and weak administrative capacity of developing-country governments often impede effective forest protection, which potentially could counterbalance these effects. The limited statistical evidence on the EKC is also inconclusive (Kaimowitz and Angelsen, 1998). For example, one recent study finds no statistically significant relation between deforestation and per capita income (Koop and Tole, 1999).

\subsection{The land degradation-deforestation hypothesis}

Many tropical farmers practise unsustainable farming methods. After a few years of cultivation, loss of soil fertility and weed problems force them to move on and clear additional forest somewhere else. While such shifting-cultivation systems may be perfectly sustainable as long as population densities remain low, when population rises these systems may degrade the natural resources. New technologies can allow farmers to maintain productivity without degrading their resources. This, in turn, should reduce their need to abandon land and clear additional forests to make new plots. Farmers may not want to use land in an extensive fashion, but with their existing technology they have little choice.

This volume provides several examples of situations where farmers clear land, exploit it for several years and then move on to forest areas they had not cleared previously. Farmers have good reasons for behaving like this. Smallholders often have high discount rates and exhibit short time horizons, which leads them to ignore the long-term effects of land degradation on productivity. The economic context and government policies sometimes make it difficult or costly to intensify their production in a sustainable fashion. 
For example, affordable inputs may not be available when farmers need them. Lastly, as long as 'unutilized' potential farmland exists, farmers will generally find it cheaper to expand the area under cultivation than to intensify. This is one of Boserup's (1965) main hypotheses. If given the choice, farmers will expand into new areas before they intensify.

Another key question related to the land degradation-deforestation hypothesis is the following: Does sustainable intensification stop - or at least reduce - expansion and deforestation or will it accelerate deforestation by making farming more profitable? In other words, is it a question of intensification or expansion, or is the most likely outcome intensification and expansion? Many chapters of this book address that question.

\section{The Book's Aims and Scope}

\subsection{Definitions of technological progress (change)}

Technological progress (change) can be defined as an increase (change) in total factor productivity (TFP), which is a key concept in economic theory. It simply implies that farmers can produce more with the same inputs, or the same output with fewer inputs. As long as prices remain constant, an increase in TFP will increase profits.

Technological change should be distinguished from agricultural intensification. The latter can be defined as higher input use (or output) per hectare. Intensification and yield-increasing (land-saving) technological change are related terms. But change in technologies may or may not lead to intensification, and intensification can occur without any change in the underlying technology.

Some types of new technologies are embodied in inputs and capital goods, as in the case of improved seeds and fertilizers. Others are disembodied, which means that they rely entirely on new management practices or information. This volume discusses mostly embodied technological changes.

A crucial aspect of new technologies is their effect on how intensively farmers use different factors of production (mainly labour, capital and land). Do the per-hectare requirements of labour and other inputs increase or decline? Technologies may be labour-saving, capital-intensive, and so on. In Chapter 2 we provide more precise definitions of each type of technological change.

Capital-intensive technological change takes various forms. For our purposes it is critical to distinguish between those that save labour, such as tools and draught animals, and those that save land, such as fertilizers. By definition, the former reduce the amount of labour demanded per hectare. The latter often have the opposite effect. How higher capital input use affects the demand for labour depends on which of these two types of capital farmers adopt. 


\subsection{The key variables that determine how technological change affects forests}

The key question this book seeks to answer is how technological change in agriculture affects tropical forest cover. Economic theory allows us to organize the main arguments into a consistent framework and derive hypotheses that can be empirically tested. Prior to the Costa Rica workshop mentioned in the preface, we presented a list of hypotheses about the key conditioning factors and asked the authors of the case-studies to address them. The main variables that we hypothesized might affect how technological change influences forest cover were the following:

1. Type of technology: labour and capital intensity, the type of capital involved and the suitability of the technology for recently cleared forest areas.

2. Farmer characteristics: income and asset levels (poverty) and resource constraints.

3. Output markets: farmers' access to markets, the size and demand elasticity of those markets and how they function.

4. Labour market: wage rates, ease of hiring in and hiring out and feasibility of in- and out-migration.

5. Credit markets: availability and conditions (interest rate) of loans.

6. Property regime: security of property rights and how farmers acquire rights to forest.

7. Agroecological conditions: quality of land (slope, soil, rainfall) and accessibility.

In Chapter 2, we use economic theory to derive more explicit hypotheses about how many of these factors can affect the rate of deforestation. In Chapter 21, we summarize the empirical evidence from the case-studies for each of these variables.

\subsection{Isolating the technology-deforestation link}

In the process of putting together this book, we have tried to stay focused on the link between technology and deforestation. As much as possible, we have avoided entering into a general discussion of the causes of deforestation or of agricultural innovation in poor countries. We felt - and continue to feel - that to say something new we had to maintain a narrow focus. There are nevertheless several caveats. One cannot understand the technology-deforestation link without understanding the wider context. Indeed, it is precisely the interaction between technology type, farmer characteristics and context that produces particular forest outcomes.

Many factors influence the rate of deforestation. From an empirical perspective, it is hard to separate out the marginal effect of technological change. 
For example, an increase in the price of a crop suitable for frontier agriculture will directly stimulate the crop's expansion but may also indirectly promote the use of new technologies for that crop. Conversely, new technologies might induce changes in population patterns, infrastructure and policies, which all influence deforestation.

For the most part, we have tried to take technological change and adoption as exogenous and discuss what they imply for forest clearing. But it is not easy to separate adoption from the effects of technological change. Farmers must first adopt a technology before it can have an impact on forest. The theory of induced technological innovation (Boserup, 1965; Hayami and Ruttan, 1985 ) tells us that researchers develop and farmers adopt technologies that reflect the scarcity (price) of different factors. Forest frontiers tend to have abundant land and scarce labour and capital. Thus farmers will generally prefer technologies that save labour and capital rather than land. Labour-saving technologies are more likely to augment the pressure on forest because they free labour for expanding agriculture. Unfortunately, this means that the type of technology frontier farmers are mostly likely to adopt is the one most likely to increase forest clearing. If we think about it in these terms, we might say that one of this book's central themes is to explore under what circumstances Boserup might be wrong. In other words, when might farmers be willing to intensify even though they still have the option of expanding extensively? ${ }^{1}$

\subsection{Sustainable agricultural intensification}

The issues this book deals with form part of a broader agenda related to tropical agriculture and sustainable development. That agenda is concerned with finding ways to combine several objectives: (i) increased food production and farmer incomes; (ii) equitable distribution of the resulting benefits; (iii) minimal degradation of existing farmland; and (iv) minimal expansion of agricultural land into natural forests.

The book focuses on (iv), although it pays attention to the trade-offs and synergies between (iv) and the other objectives, particularly (i). While analysts normally think of the negative environmental effects of agriculture in terms of land degradation, they should not lose sight of the negative consequences of forest clearing and forest degradation. There may be a trade-off between the two types of effects. Extensive tree-based systems have low impacts on soil erosion and fertility, but may have large impacts on primary forest cover.

The simple forest-non-forest dichotomy tends to sweep a lot of these important issues under the carpet. As noted earlier, the real world includes secondary forest (fallows) in shifting-cultivation systems, tree crops, agroforestry systems and other land use, all of which provide different levels of environmental services. A number of chapters in this book touch on this issue.

Our focus on deforestation does not imply that this should be the sole - or even dominant - criterion for assessing agricultural technologies. The 
question is not whether to promote technological change in tropical agriculture, but what type of change to promote. We firmly believe technological progress in tropical agriculture is critical to increasing rural income, improving food security and contributing in general to economic growth and development. But we also believe the current rate of tropical deforestation is too high.

\section{Key Conclusions}

Below we present the main conclusions and policy lessons that emerge from the studies in this book. Chapters 21 and 22 elaborate these main ideas in greater detail.

1. Trade-offs and win-lose between forest conservation and technological progress in agriculture in areas near forests appear to be the rule rather than the exception. However, win-win opportunities exist. By promoting appropriate technologies and modifying the economic and political environment in which farmers operate, policy-makers and other stakeholders can foster them.

2. New technologies are more likely to encourage deforestation when they involve products with elastic demand (supply increases do not depress prices much). This typically applies to export commodities. The stories of commodity booms and deforestation are almost always about export crops. On the contrary, higher supplies typically depress the price of products sold only in local or regionalized markets rather rapidly. That dampens the expansionary impact of the technological change and may even override it. But it also dampens the growth in farmers' income.

3. New technologies often create economic opportunities, which tend to attract migrants. Otherwise agricultural expansion would inevitably bid up local wages, which would choke off further expansion. Commodity booms can only be sustained if there is a large pool of abundant cheap labour or the technology involved is very capital-intensive. Elastic product demand combined with an elastic supply of labour provides optimal conditions for the introduction of new crops, leading to massive deforestation. On the other hand, when productivity improvements in agriculture coincide with growing employment opportunities in other sectors, the former may not stimulate forest conversion, as demonstrated by the historical experience of the developed countries.

4. Most farmers operating at the forest frontier are capital- and labourconstrained. Thus, the factor intensities of the new technology matter a lot. Technologies that free labour may allow farmers to expand the area they cultivate or release labour to migrate to the agricultural frontier. On the other hand, labour-intensive technologies should limit the amount of family labour available for land expansion and bid up local wages, therefore discouraging deforestation. Since farmers are labour-constrained, we can - as a rule-expect them to prefer labour-saving technologies. Thus, with some important exceptions, we are not likely to get the type of technological change that would save 
the forests. Even labour-constrained farmers may adopt labour-intensive technologies if they are the only alternative available to produce certain profitable or less risky crops or to achieve some other household objective.

5. Agricultural land expansion often requires capital to buy cattle or planting material, hire labour or purchase other goods. Capital (credit) constraints can therefore limit expansion. Technological progress should increase farmers' ability to save and thus to invest in activities associated with deforestation. Similarly, higher off-farm wages can provide farmers with the capital they need to expand their operation, even though they increase the opportunity costs of labour.

6. Technological progress in the more labour- and/or capital-intensive sectors of agriculture, which are normally not close to the forest frontier, is usually good for forest conservation. Technological progress in these more intensive sectors shifts resources away from the frontier by bidding up wages and/or lowering agricultural prices. There are exceptions. For example, the new technology may displace labour and push it towards the agricultural frontier or it may generate the funds farmers use to invest in forest conversion.

7. Smallholders normally maintain several production systems. Technological progress in the more intensive systems may shift scarce resources away from the extensive ones, thus reducing the overall demand for agricultural land. But the increased surplus can also be used to invest further in the expansive system (typically cattle), increasing land demand.

Some people may find the overall tone of this book overly pessimistic about the feasibility of achieving win-win solutions. But we are convinced certain trade-offs do exist and policy-makers must sometimes make hard choices. Many policies that are good for agricultural development frequently promote deforestation, including improving access to markets, credit, transportation infrastructure and technologies (Kaimowitz and Angelsen, 1998; Angelsen and Kaimowitz, 1999). Policy-makers can make better choices if they explicitly consider the existing trade-offs and alternatives. Sometimes, they can also identify win-win solutions. In either case, decision-makers need to anticipate the possible effects of promoting different types of technologies in various contexts and cannot assume from the outset that the outcome will be win-win. It is not a matter of slowing down agricultural intensification to save forests, but rather of identifying technologies and intensification strategies that come as near to win-win as possible.

\section{The Contributions}

Chapter 2 provides a theoretical overview. After that, we have arranged the chapters geographically. We start with two studies of the historical experience in developed countries (Chapters 3 and 4), followed by eight chapters on Latin America (5-12), four on Africa (13-16) and four on Asia (17-20). Then come a summary and a set of policy recommendations (Chapters 21 and 22). 
Arild Angelsen, Daan van Soest, David Kaimowitz and Erwin Bulte spell out the theoretical framework in Chapter 2. First, they provide precise definitions of technological change and classify technological change into different types, based on their factor intensities. The theory discussion starts off with a single farm household. Two key concepts for understanding how that household will respond to technological changes are economic incentives and constraints. The former relate to how new technologies influence the economic return of different activities. The latter have to do with how the technologies modify the labour and capital constraints that farmers face. Then, the chapter shifts to the macro level and discusses how aggregate changes in output supply and input demand affect prices, wages, migration and investment.

In Chapter 3, Alexander Mather examines the historical role of technological change in agriculture in Denmark, France and Switzerland. During the 19th and 20th centuries, many European countries underwent a forest transition: forest cover stopped declining and began to rise. New agricultural technologies contributed to this transition. Together with improvements in the transport network, they helped break the link between local population size and agricultural area. Marginal land went back to forest. Nevertheless, technological progress was only one of several radical societal changes that took place and it is difficult to assess its specific contribution. Industrialization created new urban jobs and stimulated a rural exodus. Coal replaced fuel wood as the main source of energy supply. The state emerged as a legislative and technical agent for environmental management.

Thomas Rudel provides a related story from the American South during the period from 1935 to 1975 in Chapter 4. Yield increases in the more fertile areas put farmers in more marginal areas out of business and their lands reverted to forests. The type of technological change influenced the increase in forest cover, since fertilizers and mechanization were both more suited to the more productive lands. Even though mechanization displaced labour, it did not promote deforestation because the expelled labour moved to the cities. In a context of rising opportunity costs for labour, land degradation led to the reforestation of marginal lands, which could no longer compete in agriculture.

In the first chapter on Latin America, Chapter 5, Andrea Cattaneo presents a general equilibrium analysis of a wide range of technological options for the Brazilian Amazon. An increase in TFP increases deforestation nearly always in the short run and always in the long run. Labour-intensive technologies for perennials reduce deforestation sharply. In annuals, this occurs in the short run, but in the long run labour and capital migrate to the Amazon to take advantage of the profits offered by the new technology and the net result is more deforestation. Capital-intensive technological change involving livestock and perennials lowers deforestation in the short run, since farmers are capital-constrained. But in the long run deforestation greatly increases. Cattaneo concludes that there are trade-offs between income generation, food security, equity and deforestation. Technological change in perennials is good for deforestation and equity, while livestock innovations are 
good for income and food security. Improvements in annual crops are not a preferred choice for any of the objectives.

Livestock researchers in Latin America have argued for some time that intensifying pasture systems can help reduce deforestation. Douglas White, Federico Holmann, Sam Fujisaka, Keneth Reategui and Carlos Lascano critically examine this claim in Chapter 6. Based on evidence from three research sites in Peru, Colombia and Costa Rica, they conclude that it is not so much that pasture technologies reduce deforestation but rather that forest scarcity resulting from past deforestation encourages ranchers to adopt more intensive pasture technologies. Forest scarcity drives up land prices, which make intensive growth more attractive than extensive growth. The authors conclude that research should focus less on how intensification affects deforestation and more on finding ways to make deforestation and extensive land use less attractive for farmers.

In Chapter 7, Stephen A. Vosti, Chantal Line Carpentier, Julie Witcover and Judson F. Valentim provide a detailed study of farmers' options for pasture and cattle production systems in the western Brazilian Amazon. Using a linear programming farm model, they find that many of the more intensive production systems are attractive to farmers and they adopt them. However, these more intensive systems will increase the pressure on remaining forest on farmers' land. The intensive systems are more profitable and the extra profits help relax farmers' capital constraints. Although the authors conclude that improved pasture technologies are a win-lose rather than a win-win alternative, they note that policy-makers may be able to offer ranchers more profitable livestock alternatives in return for a commitment to conserve their forest.

Peter Roebeling and Ruerd Ruben use a methodology similar to the previous chapter in their study from the Atlantic zone of Costa Rica, presented in Chapter 8. They compare the effectiveness of technological progress and price policies in improving agricultural incomes and reducing deforestation. Technological progress generally generates larger income effects than economic policies and leads to similar levels of deforestation. Better pasture technologies stimulate deforestation on large farms, again suggesting a win-lose situation. The authors are optimistic, however, that, with an appropriate mix of policies, policy-makers should be able to simultaneously increase incomes and reduce deforestation.

The next chapter (9), by Francisco Pichon, Catherine Marquette, Laura Murphy and Richard Bilsborrow, describes the results from detailed household surveys of smallholder settlers in the Ecuadorean Amazon. The adoption of a labour-intensive crop, coffee, in a context where households are labourconstrained has limited deforestation on most farms. Farmers grow coffee even though it is labour-intensive and does not provide the highest immediate income. Coffee has, however, a guaranteed market and low transportation costs and is important for farmers' long-term income security. Some farmers have gone for systems involving greater forest clearing, usually based on cattle raising. Farmers who obtain more capital as a result of productivity increases 
or improved access to credit usually invest it in cattle, which uses a lot of land but little labour, or coffee, using hired labour. This implies a win-lose-type situation, where the same factors that restrict farmers' forest clearing also limit their incomes.

Still in Ecuador but in a different context, Sven Wunder analyses the banana booms in Chapter 10. The initial production systems farmers adopted shortly after the Second World War used land in an extensive fashion and required the farmers to frequently change locations. The technologies were labour-intensive. But, rather than reducing deforestation, the expansion of banana production stimulated massive in-migration, which was associated with much greater forest clearing. Roads built for bananas opened new areas to cultivation. During a second period, the introduction of the 'Cavendish' variety and mechanization made banana-growers demand less land and labour. The fragility of the 'Cavendish' variety made frontier regions with poor transportation infrastructure less suited for bananas. Stagnant banana markets combined with higher yield reduced banana-related deforestation, although the decline in employment on the banana plantations provoked some forest loss, as unemployed banana workers began clearing forest to grow other crops. The population shifts and infrastructure developed during the initial boom had lasting effects, which carried on into later periods. From a comparative perspective, the deforestation resulting from Ecuador's banana boom was probably less than would have occurred with similar booms of other agricultural products, since bananas are comparatively higher-value crops that require lots of labour and capital per hectare.

Soybeans in Brazil and Bolivia present us with a more recent commodityboom story. Over the past three decades, the new crop has had a profound impact on land use, as David Kaimowitz and Joyotee Smith document in Chapter 11. Brazilian farmers now plant almost 13 million ha of soybean, a crop virtually unknown in that country 50 years ago. The production system is very capital-intensive and uses much less labour than most alternative land uses. In the Brazilian Cerrado and Santa Cruz, Bolivia, soybean cultivation directly replaced the natural vegetation. In the Brazilian South, where it mainly replaced other crops, soybean expansion displaced large numbers of agricultural labourers and small farmers, who could not afford the high capital costs. This induced a great push-migration to the frontier regions of the Amazon and Cerrado. Kaimowitz and Smith also note that new soybean technologies and policies favouring soybean expansion reinforced each other and lifted production levels high enough to justify the creation of a massive infrastructure of roads, processing facilities and input distribution outlets. They also favoured the emergence of a powerful soybean lobby, which was able to ensure long-term government support for the crop.

Shifting cultivators are the focus of many controversies. One relates to their share of tropical deforestation. Another concerns how getting shifting cultivators to adopt more intensive technologies might affect their land-use patterns. In Chapter 12, David Yanggen and Thomas Reardon analyse how 
the introduction of kudzu-improved fallows affected the demand for forest by shifting cultivators in Peru. Kudzu is a leguminous vine that speeds up soil recuperation. This allows farmers to use shorter fallow periods, which in principle should reduce their need for agricultural land. But kudzu also saves labour and increases productivity, which pull in the opposite direction. On balance, the authors' household data show that kudzu induced a shift from primary to secondary forest clearing, with a modest increase in total forest clearing.

Beginning with Chapter 13, we move to Africa. Thomas Reardon and Christopher Barrett discuss the challenge of sustainable agricultural intensification (SAI), broadly defined as production systems that allow greater production without depleting soil nutrients or otherwise degrading the natural resources. Most farmers on the continent are intensifying without investing enough in maintaining soil fertility. Such soil mining eventually leads them to expand their production on to fragile lands. Reardon and Barrett argue that economic liberalization in a context of poorly functioning markets has made it more difficult for farmers to adopt an SAI path. In particular, reductions in fertilizer subsidies and government credit programmes have induced farmers to mine their soils and adopt more extensive agricultural systems.

The following chapter (14) looks at many of the same issues within the specific context of northern Zambia. Stein Holden gives a historical treatment of two major technological changes during the 20th century: the introduction of cassava in the chitemene shifting-cultivation system and the adoption of a more capital-intensive maize cultivation system. The chitemene system required each household to clear significant amounts of forest, but market imperfections limited total deforestation. The introduction of cassava improved yields and increased the number of people agriculture could support in the region. It also reduced labour requirements and made production less risky. In the short run it reduced deforestation. But in the long run and in areas with better market access it had the opposite effect, since it permitted higher population densities and a surplus to sell to markets. In the 1970s, government credit and price policies encouraged the adoption of hybrid maize, grown with fertilizers. In the short run this reduced deforestation, as farmers cut back their chitemene area. Holden notes, however, that the long-run outcome might not be so favourable, since the fertilizers acidify the soils. Many farmers have abandoned the maize-fertilizer system in response to structural adjustment policies and gone back to chitemene systems, and deforestation has increased as a result.

In Chapter 15, Robin Reid, Philip Thornton and Russell Kruska review how trypanosomosis, a major livestock disease, affects the African landscape and how efforts to control it might change that landscape. Disease control can encourage the use of animal traction, which permits farmers to cultivate about twice as much land as cultivating with hand-hoes. Based on remote-sensing data and other spatial data, the authors conclude that disease control 
encouraged agricultural expansion in the Ghibe valley in south-west Ethiopia, their study area. People moved toward lower-elevation areas and cleared land for cultivation near the rivers. But they also point out that many areas that have trypanosomosis lack the conditions that might lead disease control to induce significant deforestation.

Over the past four centuries, cocoa has moved from country to country, constantly bringing deforestation in its path. In Chapter 16, François Ruf reviews the two most recent touchdowns of the cocoa cyclone, Côte d'Ivoire and Sulawesi in Indonesia. It costs less to grow cocoa in recently cleared forest than in old cocoa plantations. This and the ageing of the cocoa farmers after several decades of cocoa boom provide the main driving forces behind the continuous shifts in location. Farmers are only likely to find it worthwhile to replant and intensify cocoa production once forest has become scarce. Thus, like White et al., Ruf concludes that deforestation triggers technological change. It is not just the other way around. The cocoa-boom story resembles the banana-boom case, presented by Wunder, in several aspects: abundant and accessible forest, a large reservoir of potential migrants and (expectations about) rising prices. Ruf reviews several technological changes in cocoa cultivation in the two countries and shows how, in most cases, they encouraged deforestation. He also argues that the adoption of green-revolution technologies in the lowlands of Sulawesi stimulated deforestation in the uplands by displacing labour and providing investment capital for cocoa expansion.

This upland-lowland dichotomy is central in Asian agriculture. In Chapter 17, Sisira Jayasuriya uses a trade-theoretic analysis to discuss how the two sectors interact. He systematically reviews what impact various technological changes in either of the sectors will have on upland deforestation in situations with fixed and endogenous prices, with and without migration, with capital- and labour-intensive technologies, with distinct types of property rights and with different upland-crop income elasticities. Jayasuriya argues that improving the productivity of crops like rubber, tea, oil-palm and coffee, which compete for land with forest, will aggravate deforestation. The Green Revolution in wet-rice agriculture, which depressed real food prices and increased agricultural employment, may have had a significant pro-forestry effect. However, one cannot assume that low lowland food prices will always have a benign effect on forests. Lower food prices raise incomes and that can stimulate demand for upland products, such as vegetables, and actually increase deforestation.

Chapter 18 provides a concrete example of favourable lowland-upland interactions. Gerald Shively and Elmer Martinez use farm-level data to document how technological change in lowland agriculture in Palawan, Philippines, gave a win-win outcome. Irrigation investments reduced the amount of labour required per hectare during each cropping season but increased the number of crops per year, leading to higher overall labour demand. This resulted in more job opportunities and higher wages for upland households, 
who responded by reducing the amount of land they cleared by almost half. The households cut back mostly on cash-crop (maize) production, rather than subsistence-crop (rice) cultivation, which remained practically constant.

In Chapter 19, Ian Coxhead, Gerald Shively and Xiaobing Shuai analyse the implications of technology changes in maize and vegetable production in Mindanao, the Philippines, in the broader context of agricultural and macroeconomic policies. The authors discuss how changes in the level and variability of yields and prices determine cultivated area. Reducing the variability of maize yields reduces total area, presumably because farmers no longer have to cultivate so much maize to guarantee food security (a kind of 'full belly' effect). Reducing vegetable-crop yields has no effect on total areas or may even have the opposite effect. Improvements in technology do not induce farmers to increase their area in vegetable areas, in part because they are credit- and labour-constrained. They cannot hire outside labour for vegetables, because the crop requires special skills and high-quality care.

The last case-study in the volume is by Wil de Jong. In Chapter 20, he deals with the impact of rubber on the forest landscape in Borneo (Indonesia and Malaysia). Although many associate rubber with deforestation, de Jong finds that the crop contributed little to encroachment into primary forest in his study areas. In fact, it encouraged farmers to restore agroforests in certain areas, since the typical rubber production system combines planted rubber with natural regeneration. The fact that the study areas were isolated areas with low migration contributed to this outcome. In addition, farmers had a reservoir of old fallow land where they could plant rubber, and local authorities and the national government restricted forest conversion. In locations with other characteristics, introducing rubber might have led to a rather different outcome.

Chapter 21 summarizes the key insights from the above case-studies. First, it discusses the technology-deforestation link in six different types of cases: developed countries, commodity booms, shifting cultivation, permanent upland (rain-fed) agriculture, irrigated (lowland) agriculture and cattle production. Next, it returns to the hypotheses presented in section 3.2 and Chapter 2, and discusses the key conditioning factors in the technologydeforestation link. A number of factors determine the outcome. Among these, labour-market effects and migration are critical in a majority of the cases. Another critical effect is that new technologies can help relax farmers' capital constraints, which may lead to higher or lower deforestation, depending on how they invest their additional funds.

Chapter 22 offers policy recommendations. It presents some typical win-win and win-lose situations. It also relates the issues this volume discusses with the current trend towards greater economic liberalization and globalization and with the overall policy objectives of poverty reduction and economic growth. 


\section{Note}

1 To be fair, Boserup $(1965,1981)$ acknowledged that population growth (land scarcity) is not the only factor that drives technological progress and intensification.

\section{References}

Angelsen, A. and Kaimowitz, D. (1999) Rethinking the causes of deforestation: lessons from economic models. World Bank Research Observer 14(1), 73-98.

ASB (1994) Alternatives to Slash-and-Burn: a Global Strategy. ICRAF, Nairobi.

Boserup, E. (1965) The Conditions for Agricultural Growth: the Economics of Agrarian Change under Population Pressure. George Allen \& Unwin, London, and Aldine, Chicago.

Boserup, E. (1981) Population and Technological Change: a Study of Long-Term Trends. University of Chicago Press, Chicago, and Basil Blackwell, Oxford.

Food and Agriculture Organization (FAO) (1997) State of the World's Forest, 1997. FAO, Rome.

Gockowski, J., Blaise Nkamleu, G. and Wendt, J. (2000) Implications of resource use intensification for the environment and sustainable technology systems in the Central African rain forest. In: Lee, D. and Barrett, C. (eds) Tradeoffs and Synergies: Agricultural Intensification, Economic Development and the Environment. CAB International, Wallingford, UK, pp. 197-220.

Hayami, Y. and Ruttan, V.W. (1985) Agricultural Development: an International Perspective. Johns Hopkins University Press, Baltimore.

Kaimowitz, D. and Angelsen, A. (1998) Economic Models of Tropical Deforestation: a Review. Center for International Forestry Research (CIFOR), Bogor, Indonesia.

Koop, G. and Tole, L. (1999) Is there an environmental Kuznets curve for deforestation? Journal of Development Economics 58, 231-244.

Mellor, J. (1999) Pro-poor growth - the relation between growth in agriculture and poverty reduction. Unpublished paper prepared for USAID.

Tomich, T., van Noordwijk, M., Budidarsono, S., Gillison, A., Kusumanto, T., Murdiyarso, D., Stolle, F. and Fagi, A.M. (2000) Agricultural intensification, deforestation, and the environment: assessing tradeoffs in Sumatra, Indonesia. In: Lee, D. and Barrett, C. (eds) Tradeoffs and Synergies: Agricultural Intensification, Economic Development and the Environment. CAB International, Wallingford, UK, pp. 221-244.

World Bank (1991) World Development Report 1991: the Challenge of Development. Oxford University Press, Oxford. 